$$
\text { "tmcs-mate" — 2011/5/14 — 0:28 — page } 117 \text { — \#1 }
$$

\title{
Cooperative learning in teaching mathematics: the case of addition and subtraction of integers
}

\author{
ILEANA MATE
}

Abstract. In the course of teaching and learning mathematics, many of the problems are caused by the operations with integers. My paper is a presentation of an experiment by which I tried to make the acquisition of these operations easier through the use of cooperative methods and representations. The experiment was conducted in The LowerSecondary School of Paptamási from Romania, in the school year 2009-2010. I present the results of the experiment.

Key words and phrases: C30, C60, F40, Q30, Q60.

ZDM Subject Classification: cooperative method, integers, addition and subtraction of integers, representations, material, visual, symbolic representations.

\section{Introduction}

In the course of teaching mathematics, there are such items, which are serious difficulties for generations. One of these items is comprised in the $6^{\text {th }}$-grade syllabus: addition and subtraction in the set of integers, with subtraction being the most difficult one. Many adults have a nightmarish memory of the "minus out of minus" rule. Characteristically, the internet search programme gives out 251, 000 findings in English and 289, 000 in Hungarian. Among these, there are articles, remedial materials, references to textbooks etc. In the experiment I have undertaken, I looked for solutions to overcome these learning and teaching difficulties. The experiment has been conducted in a country school attended by 


$$
\text { "tmcs-mate" — 2011/5/14 — 0:28 — page } 118 \text { — \#2 }
$$

good-intentioned, well-behaved, hardworking pupils who are not selected, elite children.

The Romanian schooling system provides that children should start their first school year at the age of 6-7. The first four years - the elementary classes - are taught by one single primary-school teacher. Here, there are no marks but only qualifiers: very good, good, sufficient and insufficient. From the $5^{\text {th }}$ grade up to the $8^{\text {th }}$ grade, the students attend lower-secondary school, where every subject is taught by a different teacher. Each class has a form teacher, who is responsible for the organisation and education of the respective class, in addition to teaching a certain school subject. From now on, the students get marks from 1 to 10 , with 5 being the minimum passing mark and 10 the maximum. After that, the students continue their professional or theoretical education for other $3-5$ years.

The experiment was conducted in The Lower-Secondary School of a small village from Romania, Paptamási, in the school year 2009-2010. This is the only school in the village of Paptamási that has lower/secondary classes. This is why all the children from the appertaining smaller villages Kügypuszta, Nyüved and Pelbárthida come to Paptamási to attend lower-secondary school, because in these villages there is only primary school. The experimental class $6 \mathrm{~B}$ consisted of 17 pupils of Hungarian mother tongue studying in Hungarian.

The experiment lasted for 18 teaching hours, and comprised getting acquainted with integers, their representation on the number line, the introduction of the notions of opposite and absolute values, and operations within the set of integers. Here I will present the parts of the experiment regarding the addition and the subtraction of integers. Two basic methods were employed in the course of the experiment: cooperative work and the use of concrete visual representations.

The main question of the experiment: In what measure the cooperative method and the use of concrete visual representations make the addition and the subtraction of integers more efficient?

\section{Theoretical framework \\ Cooperative learning}

The method of cooperative learning was developed by S. Kagan.

The traditional classroom work is based on competition. When we speak of cooperative learning, we think of such teaching methods that are due to enable the students' cooperative interaction as an organic part of the learning process. This 
interaction may be very basic, when the students find the answer to a question together working in pairs, or may imply complicated team-building activities, when each member of a group adopt a well-established role and task.

\section{Groups}

While groups are generally random as to composition, number of constituents, and have no identity, the cooperative groups tend to always be formed of the same four individuals, bearing a strongly positive consciousness of togetherness, their members accepting, knowing and helping each other. The cooperative groups are generally heterogeneous, with boys and girls having a different level of performance, a different language background, belonging to different ethnical groups. The forming of such groups may certainly happen at random, too, but then consistent reorganisation of the groups is needed in order to prevent the forming of defeated groups.

\section{Assessment}

In the course of using the cooperative learning, the students' marks may often depend on one another. According to the researches, the common assessment of the groups influences their effort to fulfil the aim to a great extent. Nevertheless, it is important to mention two difficulties of this kind of assessment:

- If a student performs badly for a longer period of time, he/she may raise his/her colleagues' repugnance because of being an obstacle in obtaining a better mark.

- If the group mark is transferred to the school report, the performance of the group-mates will improve some individual marks and make others worse.

According to S. Kagan: "In those classes where the students work in groups, the easiest way of improving the spirits is to establish a class aim, and to reward the whole class after its fulfilment. If the groups are continuously in competition with one another, or we exclusively use a competitive assessment, what we attain is only a war between the groups. On the other hand, if we employ a cooperative system of assessment, the positive "sense of us" is formed, when each student feels that he/she is part of the class and can identify himself/herself with the success of his/her classmates." (S. Kagan, 2001) 


$$
\text { "tmcs-mate" — 2011/5/14 — 0:28 — page } 120 \text { — \#4 }
$$

\section{Basic principles}

The following four basic principles define the cooperative learning. If one of them is not effective, we cannot speak of cooperative learning.

We speak of the constructive interdependence when the development of one student is dependent on the development of another student, when the success of one group is dependent on the success of another group.

The individual consciousness of responsibility greatly contributes to the success of the cooperative methods. This can have several forms. One is the method of "score responsible", by which each member of the group writes an individual test, and the average of the obtained scores will be the score of the group. Another method may be that of "responsible with tasks", by which each member of the group has his/her own task for which he/she is responsible. If we do not use individual assessment, some of the student will easily become "fare-dodgers" or "draughts".

The equal participation is an organic part of the process of learning. The students will learn only if they interact with one another and with the material to be learnt.

Parallel interactions occur during the cooperative learning. This is one explanation for the fact that cooperative learning is more efficient than traditional teaching. During the lessons where traditional methods are used, usually the teacher speaks, or at most one student. Thus the time given to the participation of one student is very short.

\section{Representations}

According to Bruner, we can speak of outer and inner (mental) representations in relation to the processing of information. In both types, we can distinguish three planes:

- Material plane: the acquisition of knowledge takes place through concrete material activities. Its inner appearance is the occurrence of the material action (action in space and time).

- Iconic plane: the acquisition of knowledge takes place with the help of graphic images. Mentally, we can speak of inner images, concepts (for example we can imagine a trapezium etc.).

- Symbolic plane: the acquisition of knowledge takes place using language and symbols. Mentally, the operation and actions with these symbols constitute the inner representations. 
In relation to our topic, for instance, the material representation for the negative integers could be the temperature, or debt (represented by discs), or a movement in a certain direction. The iconic representation could be done through marking of the movement on the number line, or the vector of movement, drawing an adequate number of discs. The symbolic representation means the use of number symbols.

Unfortunately, in the teaching of mathematics - even worldwide - we pass on to the symbolic plane too soon. According to many teachers, mathematics is the science of thinking, therefore operations have to be done mentally, and we have our students operate symbolically too soon. The operations with numbers often mean the mechanic use of rules regarding signs and symbols in lower-level classes, as well. Because the efficiency of this is low in the case of many students, we mostly dealt with the use of the three kinds of representation in our experiment. We emphasize here that we do not favour one kind of representation when we speak of the importance of visual representations. We consider that it is important to make a transition between the representations. The aim is for as many students as possible to understand that one and the same mathematical concept has different representations. Much emphasis must be given to this, because to some students the three representations of a single concept may mean totally different things.

\section{Procept}

D. Tall and E. Gray introduced the notion of procept (the first part "pro" stands for the word process and the second part "cept" stands for concept). For example, the expression $(-2)-(-5)$ may mean one process, namely the operation of subtraction, when we have to subtract the number $(-5)$ from the number $(-2)$. On the other hand, the same expression may mean the result of subtraction, the difference of the two numbers. In this sense, we can speak of the process of the operation of subtraction, or of the concept of difference. The numbers themselves are procept, and of course the algebraic expressions as well. The two meanings may cause an enormous problem to the students. Some of them remain at the process level as soon as the beginning. They perform the addition $6+4$ by counting on their fingers to 6 , then counting 4 more, and finally from 1 to 10 . Some children start from the bigger number 6 and count 4 to obtain the final result. The best students can use known fact, namely that 6 is $1+5$ and $1+4$ is 5 again, so together it makes 10 . 


$$
\text { "tmcs-mate" — 2011/5/14 — 0:28 — page } 122 \text { — \#6 }
$$

Ileana Mate

\section{Concept image}

D. Tall and S. Vinner introduced this notion in the international literature on the didactics of mathematics. It means to the name of a concept associated mental connections, definitions, pictures, concrete events, tables, charts, experiences and sometimes the classroom context when the concept was discussed. The chances to recall the concept from memory are greater if there are different connections between the neurons in our brains regarding the respective concept.

The operations are concepts, too, and their teaching needs building up a rich concept image. This is why we used four different models for the addition and the subtraction of integers in our experiment.

\section{Mathematical bases}

Our models make the operations to be more comprehensible for the pupils because these are close to the everyday interpretation. Of course, this is not the reason why we interpret the rules of operations in a familiar way in mathematics. When we introduce a new number sets, we use the so-called principle of permanence. For example, in the subtraction of negative integers, the following series of operations can lead to the rule:

$$
\begin{aligned}
& (+5)-(+2)=(+3) \\
& (+5)-(+1)=(+4) \\
& (+5)-0=(+5) \\
& (+5)-(-1)=(+6) \\
& (+5)-(-2)=(+7)
\end{aligned}
$$

The rule operative with positive integers - if in a subtraction the minuend is invariable and the subtrahend is reduced by 1 , the result increases by 1 - is to be kept operative with negative integers as well, so we can reach to the known rule of subtraction.

Some concrete treatment from the international practice

In the international practice of teaching mathematics, the models of temperature, debt - wealth or movement are used the most often in the teaching of operations regarding the addition and the subtraction of integers. We present an example of subtraction of integers from a German textbook . (Mathe Netz Gymnasium 6, Westerman Verlag, Braunschweig 2006, 215-217) 
(1) Introductory exercise: The number line is drawn on the floor of the classroom, with the distance between two neighbouring numbers corresponding to the walking pace of an average child. There are two basic view-points: in what direction the pupil looks (positive or negative direction), he/she steps forward or backwards. The sign of the number indicates the direction he/she looks in, the addition corresponds to stepping forward, and the subtraction corresponds to stepping backwards. For example, in the case of $(+2)-(-2)$, the pupil stands on point indicating $(+2)$ on the number line. Because $(-2)$ is to be subtracted, he/she steps backwards looking in the negative direction, reaching to the point of $(+4)$.

(2) The model of debt - wealth. A concrete example of income and outcome from a saving book is given. If we had $-15 €$ in the bank and we put $120 €$ on the account, how much does the deposit worth?

(3) Subtraction is the reversed operation of addition. The subtraction above can also be interpreted in terms of the question how much we have to add to $(-2)$ in order to have the result of $(+2)$. The textbook represents the adequate operations with guided sections, too.

Meanwhile, the book discusses the concept of absolute value as well, and also formulates the rules of addition and subtraction in words using this concept. It can be helpful to formulate the rules in terms of actions to perform. For example, two numbers with different signs and absolute values are added by establishing the sign of the number with the biggest absolute value first, then the less absolute value is subtracted from the biggest, and the final result will have the sign of the number with the biggest absolute value. The rule is illustrated with three examples. In the case of subtraction, it is illustrated with guided sections that the subtraction of a number means the addition of its opposite number. An integer is subtracted from another by adding the first one with the opposite of the second one. Similarly, three examples are given.

The second exemplification of subtraction of integers is taken from the Hungarian Mozaik textbook series, presenting the treatment for the $5^{\text {th }}$ grade (Sokszínü matematika 5, 2005)

The introduction of negative numbers is done through the models of temperature and altitude relative to the sea-level, after that we can also introduce the concept of absolute value.

The operations of addition and subtraction are presented through the model of debt - wealth. The red discs represent 1 forint each, while the blue squares represent a debt of 1 forint each. One red disc and one blue square make together 
a wealth of 0 forint. The students can act the operations with cards. An arbitrary number of red and blue card pairs can be given out, because the state of wealth does not change. We do not give full details of addition, because the two packs only have to be put together and the final result is given by the number of the remaining cards after the pairs of opposite cards are put aside. The subtraction is explained with the example of $(-1)-(+3)$. We take a blue square, from which we must to take away three red discs. So we put three pairs of squares and discs near our blue square. After we take 3 red discs away we have 4 blue squares the result of the subtraction is $(-4)$.

The textbook also contains the drawings of the operations above, the taking away of cards being marked by crossing out the respective cards. Of course, everything is written down with numbers, too. Thus all three planes of representation are present, so that the students could hopefully interpret the different representations as the same mathematical operation. After a few concrete examples (depending on the students), they only operate the actions mentally and write down the operations and their result symbolically.

After that, the connection of addition and subtraction follows. With the help of cards, we present that the subtraction of any number can also be performed with the addition of its opposite. This is formulated as a rule, too, in the textbook.

\section{The course of the experiment}

The experiment started with a pre-test, in which each pupil had to use all the knowledge of natural numbers acquired in the $5^{\text {th }}$ grade.

Pre-test:

1. Write with figures.

a. fifty-five thousand five

b. five thousand fifty

c. one hundred and one million one thousand fifty

d. five million five hundred and three thousand nine hundred

2. Mark the given numbers on the number line.

a. $0,30,7,45$

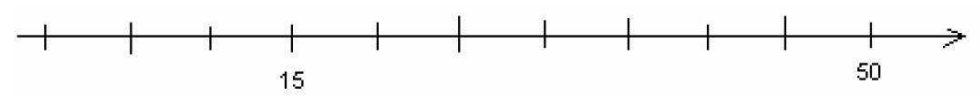


b. $15000,30000,10000$

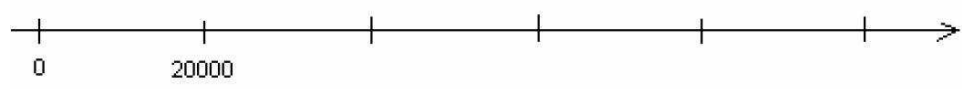

c. Write the corresponding number under the $*$ mark.

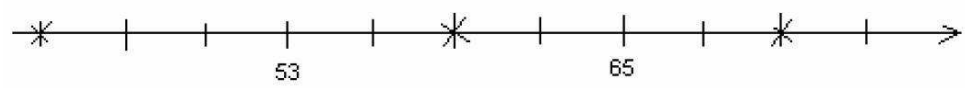

3. Which numbers make the following inequalities true?

a) $63+\square<80$

b) $\square \cdot 2+20 \geq 30$

4. Perform the following operations:
a) $5947+17096=$
b) $86416-7987=$
c) $4801 \cdot 207=$
d) $5438: 7=$
e) $15312: 72=$
f) $(13)^{2}=$

5. Calculate the following operations:
a) $23+7 \cdot 4-10: 2=$
b) $2 \cdot(32+8 \cdot 4): 2=$

6. Bence has got 23 more car cards than Ákos has. Together they have got 103 cards. How many cards has Ákos got?

Scoring:

\begin{tabular}{|l|l|l|l|l|l|l|}
\hline 1. & a.- 0.25 & b.- 0.25 & c.- 0.25 & d.- 0.25 & & \\
\hline 2. & a.- 0.4 & b.- 0.3 & c.- 0.3 & & & \\
\hline 3. & a.- 0.5 & b.- 0.5 & & & & \\
\hline 4. & a.- 0.15 & b.- 0.15 & c.- 0.15 & d.- 0.15 & e.- 0.2 & f.- 0.2 \\
\hline 5. & a.- 0.5 & b.- 0.5 & & & & \\
\hline 6. & 1 & & & & & \\
\hline
\end{tabular}

Total score: 6 points 


$$
\text { "tmcs-mate" — 2011/5/14 — 0:28 — page } 126 \text { — \#10 }
$$

Qualifiers:

\begin{tabular}{|l|c|c|c|c|}
\hline Number of points: & $<0.5$ & $0.5-2.4$ & $2.5-4.4$ & $4.5-6$ \\
\hline Qualifier: & insufficient & sufficient & good & very good \\
\hline
\end{tabular}

Interpretation of test:

\begin{tabular}{|l|c|c|c|c|}
\hline Result: & insufficient & sufficient & good & very good \\
\hline Number of students: & 3 & 6 & 4 & 4 \\
\hline
\end{tabular}

\begin{tabular}{|l|c|c|c|c|c|c|}
\hline Number of problem & 1. & 2. & 3. & 4. & 5. & 6. \\
\hline Maximum score & $11,7 \%$ & $23,52 \%$ & $5,88 \%$ & $29,41 \%$ & $35,29 \%$ & $29,41 \%$ \\
\hline
\end{tabular}

I divided the class into groups of four according to the results of the pre-test and the first semester and according to the internal relationships (friendship) of the class. The groups were heterogeneous as to sex and knowledge of mathematics. We established a class aim which was an individual for everyone aim at the same time:

"After learning the given chapter, when we write a test, every qualifier should be at least sufficient, and everyone should at least maintain his/her present result or improve it."

Learning trajectory

1. Pre-test -1 hour

2. The concept of integers, opposites, absolute values -1 hour

3 . The representation of integers on the number line, comparison, ordering -2 hours - Cooperative activity

4. The right-angled coordinate system -2 hours - Cooperative activity

5. Addition and its characteristics -1 hour

6. Subtraction -1 hour

7. The use of addition and subtraction -2 hours - Cooperative activity

8. Multiplication and its characteristics -1 hour

9. The set of multiples -1 hour

10. Division -1 hour

11. The set of divisors -1 hour

12. Raising to a power -1 hour 
13. The order of operations -2 hours - Cooperative activity

\section{Post-test -1 hour}

During the first few classes, the pupils acquired the basic concepts regarding negative numbers, then the addition and subtraction of integers was introduced.

Four different models of learning the operations with integers were used. Each group employed a different method of learning the addition and subtraction. First, the teacher told the whole class that the groups are to use four different methods: the discs - showing the red and blue discs to the class, the stairs - where the aid was made and of cardboard and a pawn from a board game was also used, the thermometer - which was the replica made of cardboard of a real thermometer with an arrow also made of cardboard, and the road - also made of cardboard, with a small toy-car. All the groups received its aids and a simple series of exercises. The teacher explained the use of the given aids to each group, after that they started resolving the exercises.

\section{Group I}

This group received 30 of red and blue discs, with one side of the discs being of one of the two colours. The red side represented the positive numbers, while the blue side represented the negative numbers. One red disc was worth 1 RON, while one blue disc was worth -1 RON. The worksheet contained such simple exercises of addition as:

$$
\begin{aligned}
& (+2)+(+4)= \\
& (-5)+(-9)= \\
& (+2)+(-2)= \\
& (-6)+(+4)=
\end{aligned}
$$

The students had to put on the desk as many discs and of such colour as indicated by the numbers. For example, $(-6)+(+4)=$ meant:
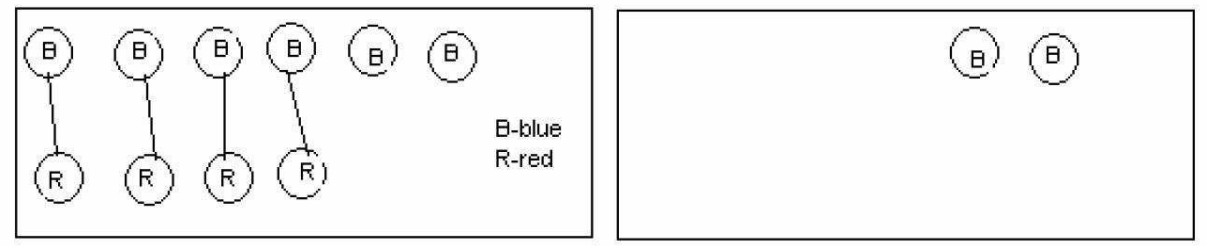
Two discs of different colours cancel each other, so they had to be put aside from the desk, and the number of the remaining discs was the final result - in the example above, the remaining two blue discs meant $(-6)+(+4)=-2$.

In resolving the exercises on the worksheet, the four pupils followed each other in doing one exercise. In case one of the members of the group had troubles, his/her classmates could help him/her by telling him/her what to do, but they could not do the exercise for him/her.

When this group had to perform a subtraction, they received a little help. For example, $(-6)-(+4)$ this would mean it: we have 6 blue discs from which we had to take away 4 red discs.

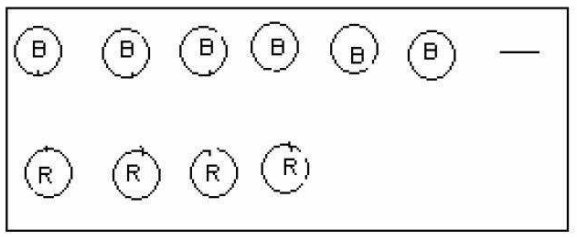

As this practically cannot be done, we take 4 more pairs of discs - that is 4 red and 4 blue discs - these valuing 0 together, and try to perform the subtraction like this.

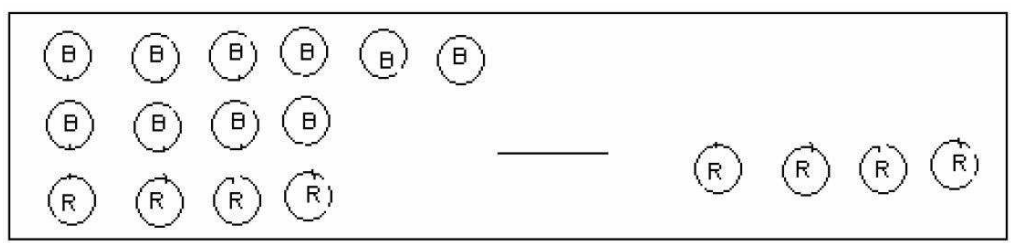

Thus we have 10 blue discs and 4 red ones from which we have to take away 4 red ones. This can be done easily, and 10 blue discs are left, therefore $(-6)-(+4)=-10$.

After doing some simple exercises, the pupils realised that it suffices reversing the subtrahend discs and adding them to the first number, and the result is the same. That is, the subtraction is the additions of opposites.

$$
(-6)-(+4)=(-6)+(-4)=-10
$$

This group did very well with the calculations, the use of this method not causing any difficulties for them. 


\section{Group II}

The second group was given a stair and a pawn. The teacher told them that the 0 step of the stair represented the ground floor, the positive numbers led to the next floors upwards, while the negative numbers led to the cellar.

The pawn always started from the middle of the stair, upwards if the number was positive, downwards if it was negative. For example: $(-2)+(+4)=$

This meant making two steps downwards, then othe four upwards.
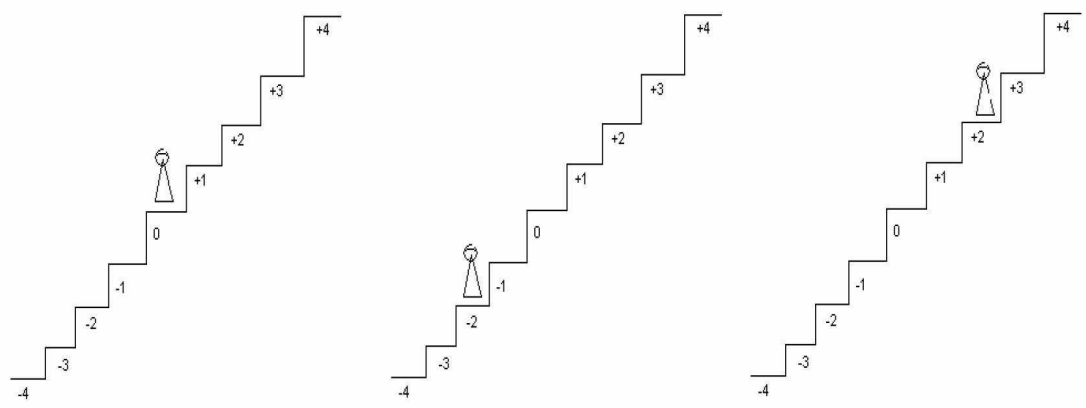

Then the pupils read the result: +2 , namely $(-2)+(+4)=+2$.

In the case of subtraction, the movements must not be according to the sign, but in the opposite direction. Thus the pupils do exactly the opposite of what the number shows. In the following example, the pawn makes three more steps downwards: $(+4)-(+3)=(+4)+(-3)=+1$.

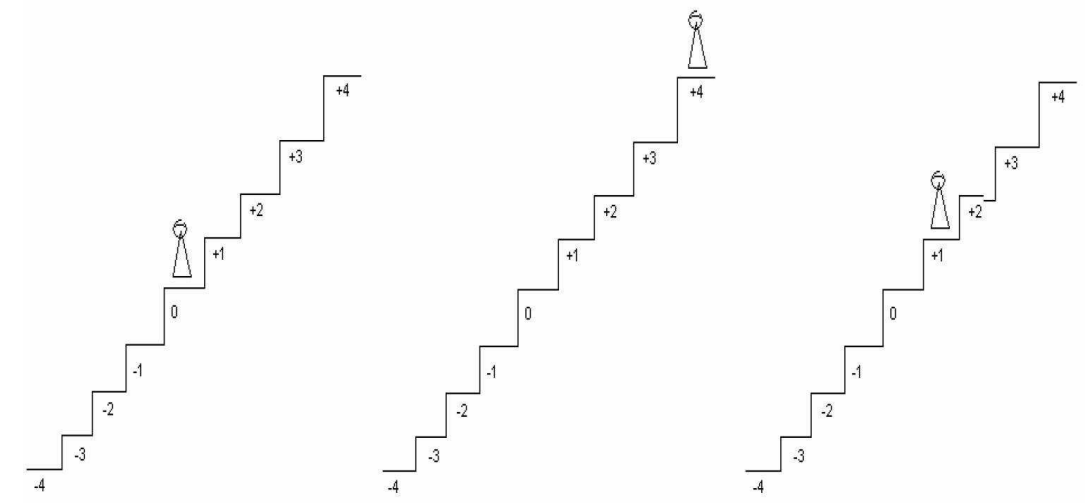

The pupils could help each other in this group, too, but they were not allowed to solve the exercise for their classmate. 


$$
\text { "tmcs-mate" — 2011/5/14 — 0:28 — page } 130 \text { — \#14 }
$$

\section{Group III}

The third group received a thermometer. The positive numbers indicated the increase of temperature, while the negative ones meant the decrease of temperature. For instance $(-5)+(+7)=+2$.

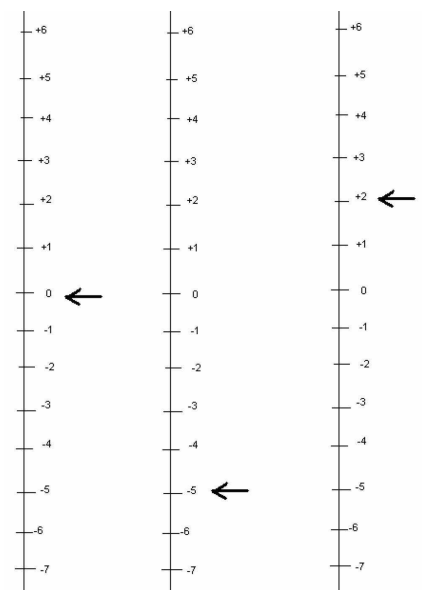

In the case of subtraction, the "-" sign modified the direction of the change of temperature. For example $(-6)-(-5)=(-6)+(+5)=-1$. This example means that now it is 6 degrees cold, and the change of temperature is the opposite of a 5-degree decrease, that is a 5-degree increase of the temperature.

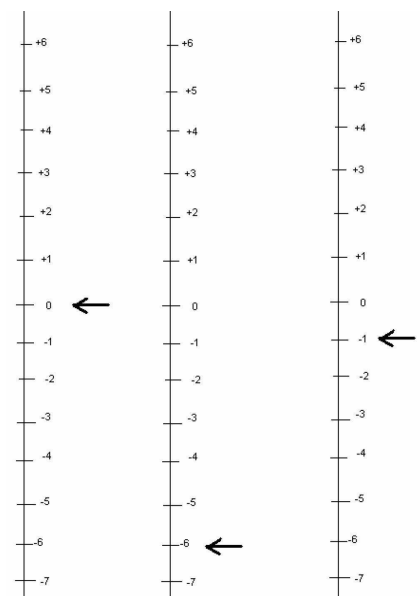




$$
\text { "tmcs-mate" — 2011/5/14 — 0:28 — page } 131 \text { — \#15 }
$$

\section{Group IV}

This group received a material that resembled a thermometer, but really it was a horizontal road, with the starting point being the students' native village, Paptamási. The positive direction was towards the nearest city, Oradea/ Nagyvárad, while the negative direction was towards the neighbouring Félegyháza.

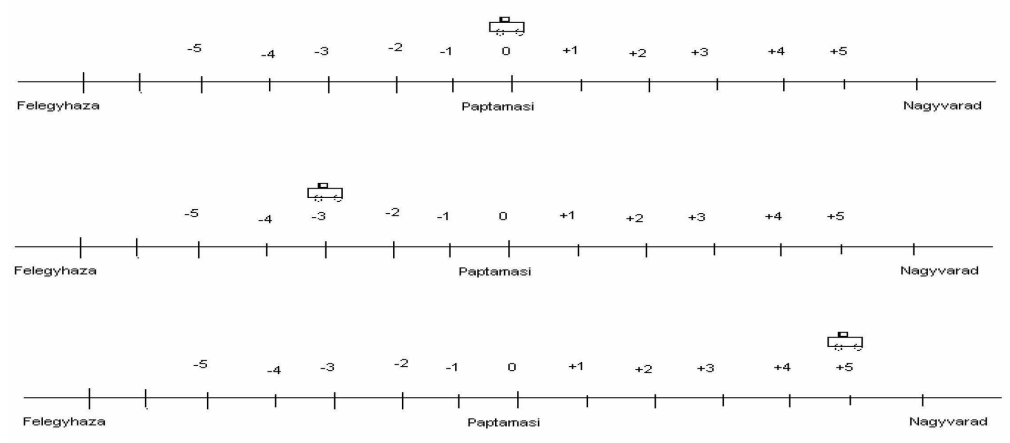

Example: $(-3)+(+8)=$

This exercise meant that we first go $3 \mathrm{~km}$ towards Félegyháza, then, from that point, $8 \mathrm{~km}$ towards Oradea/Nagyvárad

$(-3)+(+8)=+5$

Similarly, subtraction meant doing the opposite of what we should, more exactly $(+5)-(+3)=(+5)+(-3)=+2$

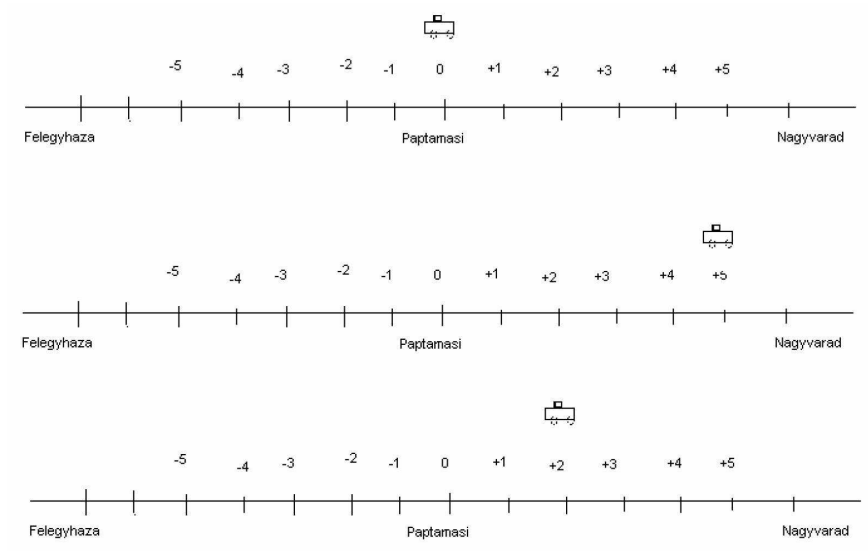




$$
\text { "tmcs-mate" — 2011/5/14 — 0:28 — page } 132 \text { — \#16 }
$$

First each pupil solved the exercises on his/her own worksheet, then they swapped places: one member of the group remained at the initial table, and the others went to other tables too learn other methods. When, at each of the tables, there was a pupil who could handle the new method well, that remaining pupil moved to another table, too. Thus all the pupils could get acquainted with all the methods, and everyone could decide which one he/she will use in the future.

Many of the better pupils realize soon how to solve the exercises without any aids. Nevertheless, during a rapid diagnostic test, many pupils asked permission to use a certain method. When we asked why they use one method or another, some pupils answered that this is because it is easier to calculate, others use it just for checking, but some pupils admitted that they were not able to calculate without any help.

After the pupils learnt the methods through easy exercises, and they could easily solve additions and subtractions, we formulated together the rule of how to add and subtract integers.

At the beginning of the experiment, we established one aim for the class. The accomplishment of this aim was checked by a post-test at the end of the experiment.

\section{Post-test:}

1. Mark the place of the numbers on the number line.

$$
\begin{gathered}
A=3 ; \quad B=\text { opposite of } 3 ; \quad C=-4 ; \quad D=|-4| ; \\
E=-|-5| ; \quad F=-7 \text { opposite of }-7 ;
\end{gathered}
$$

$G=$ the number which is greater by 3 then the absolute value of -2

2. Calculate the following operations:
a) $+5+7=$
b) $-6-2=$
c) $+10-12=$
d) $(-15)+(-7)=$
e) $(+11)-(+14)=$
f) $(-10)+(+15)=$

3. Arrange the results of the following operations in an increasing order.

$$
\begin{aligned}
& A=(-2) \cdot 3-(-18) \\
& B=(-72): 12-9 \\
& C=44+(-13) \cdot 5
\end{aligned}
$$




$$
\text { "tmcs-mate" — 2011/5/14 — 0:28 — page } 133 \text { — \#17 }
$$

$D=-38+(5-3) \cdot 4$

$E=(-2)^{3}+(-3)^{2}+(-10)^{0}$

4. Mark the following points in a right-angled coordinate-system

$$
M(+4,+3) ; \quad N(-1,-2) ; \quad P(0,+5) ; \quad R(-3,+1)
$$

5. Decide which of the following statements are true and which are false.

a) All natural numbers are positive integers.

b) Is there a whole number which is not a natural number?

c) To an arbitrary whole number there exists a smaller integers

d) There exists the greatest whole number.

Scoring:

\begin{tabular}{|l|l|l|l|l|l|l|l|}
\hline 1. & A.- 0.15 & B.- 0.15 & C.- 0.15 & D.- 0.15 & E.- 0.15 & F.- 0.15 & G.- 0.1 \\
\hline 2. & a.- 0.2 & b.- 0.2 & c.- 0.2 & d.- 0.3 & e.- 0.3 & f.- 0.3 & \\
\hline 3. & A.- 0.3 & B.- 0.3 & C.- 0.3 & D.- 0.3 & E.- 0.4 & DCBEA- 0.5 & \\
\hline 4. & M.- 0.25 & N.- 0.25 & P.- 0.25 & R.- 0.25 & & & \\
\hline 5. & a.- 0.1 & b.- 0.1 & c.- 0.1 & d.- 0.1 & & & \\
\hline
\end{tabular}

Total score: 6 points

Qualifiers:

\begin{tabular}{|l|c|c|c|c|}
\hline Number of points: & $<0.5$ & $0.5-2.4$ & $2.5-4.4$ & $4.5-6$ \\
\hline Qualifier: & insufficient & sufficient & good & very good \\
\hline
\end{tabular}

Interpretation of test:

\begin{tabular}{|l|c|c|c|c|}
\hline Results: & insufficient & sufficient & good & very good \\
\hline Number of students: & 0 & 7 & 3 & 7 \\
\hline
\end{tabular}

\begin{tabular}{|l|c|c|c|c|c|}
\hline Number of problem & 1. & 2. & 3. & 4. & 5. \\
\hline Maximum score & $29,41 \%$ & $52,94 \%$ & $5,88 \%$ & $29,41 \%$ & $23,52 \%$ \\
\hline
\end{tabular}




$$
\text { "tmcs-mate" — 2011/5/14 — 0:28 — page } 134 \text { — \#18 }
$$

\section{Reactions of the pupils, conclusions}

After the end of the experiment, we discussed with the class their experiences regarding the cooperative work. First of all, everyone sat back to his/her original group, and each group formulated why the procedure they had learnt first was good or bad. The group with discs said: "It is easy to calculate with the discs" and "We can learn the addition and subtraction of integers by playing". Those who used the stair said: "It's our favourite, because it's easy to work with it and to use it". Those who used the road only wrote: "In our opinion it's good because it's easy and playful".

After the group evaluation, everyone had to express his/her opinion individually about the best and the worst methods. Surprisingly, the preference for the discs was shared by most of the class. While the other three methods were preferred by two or three pupils each and were not preferred by as many a pupils, the discs had six fans and seven pupils who disliked it.

The six pupils who preferred the discs were among the ones who had difficulties in mathematics. Such pupils probably need mathematics to be as palpable as possible, so the use of material representations is indispensable in their case, because they can only achieve the aim in this way. The seven pupils who disliked this method were among the best learners. According to them: "it takes too much time to calculate" (A.V.), or "there is much work with it" (I.A.). They were those who could quickly solve the operations using the mathematical symbols exclusively.

After the formulating individual opinions, everyone could share it in a common discussion.

To the question if it was good to use such methods they gave the following answers:

"I think they are good because we don't have to learn the rules." (R.A.)

"Those who don't learn anything will enjoy them anyway. They can be understood without learning, too" (K.E.)

"After practising, I can see the stair even if it's not there" (R.A.)

"I don't have to learn the rules by heart. But even if I learn them by hart, I'm not sure I will understand and remember them" (S.R.)

The next topic was the question to in what measure the cooperative work is useful. First of all, the everyone's opinion was that it was a good feeling to work together within the group. Some pupils considered that: "There was more time for each of us, as if we had worked at the board." (L.M.) Some of those 


$$
\text { "tmcs-mate" — 2011/5/14 - 0:28 — page } 135 \text { — \#19 }
$$

who usually have difficulties said: "It's easier to ask a classmate than the teacher when I get stuck. I didn't have to be afraid of what the teacher would say if I made a mistake." (I.M.)

In fact, these answers contain the essence of the cooperative work:

- The members of the groups work together and help each other to understand and learn.

- Each member of the group did his/her best to understand and learn how to do the operations.

- The groups cooperated among them, as well, by teaching each other the method they had already acquired.

The method of cooperative learning fulfilled our expectations, as they helped many pupils that usually have difficulties in mathematics. We have to mention that there also are pupils to whom the traditional classroom methods are more advantageous. Such an example is A., who is a very good pupil and can understand and use the teacher's explanations very quickly, but who had nevertheless not the best results. To the question why it was difficult the answer was: "I missed the explanations of the teacher" (R.A.)

On the other hand, N. I., who is an average pupil of mathematics, learns the rules, but cannot use them in practice, favoured the method with the discs and later, when having problems with the exercises, evoked how it would look like with the discs and solved the exercise. To the question why he/she likes this method the answer was: "Because I can see what I'm calculating in front of my eyes." (N.I.)

Probably the sufficient qualifier and the fact that nobody's result in the posttest was worse were due to the employed methods and to the pupils' strength of will.

\section{Conclusions}

We could conclude that the method of cooperative learning are very good, very efficient, but we can only obtain good results if we use them in combination with other methods. Of course we don't have to use all the four procedures in class, it suffices to have the pupils get acquainted with one of them, which they can employ successfully. The teacher must also pay attention to the situation when a pupil does not attain the aims by the given method. In this case, he/she must be given the possibility to use another method. 


$$
\text { "tmcs-mate" — 2011/5/14 - 0:28 — page } 136 \text { — \#20 }
$$

It is important that the plans of concrete visual representation should be used alternatively, parallelly because the process of learning does not become monotonous, on the one hand, so the pupils do not loose their interest. On other hand, using the planes of concrete visual representation alternatively will allow each pupil to find a suitable aid by which they can store the information and learning can be efficient. As to our topic, of course we have to develop the skills of fluently operating with additions and subtractions on a symbolic plane through lots of practice. We must tolerate the use of the aids as long as necessary for some pupils. Gradually more and more pupils will be able to do the respective operations mentally, giving up the use of the aids.

\section{References}

[1] A. Ambrus, Bevezetés a matematikadidaktikába, Eötvös Kiadó, Budapest, 2004.

[2] Zs. Barabás, Matematikai munkafüzet, Corvin kiadó, Déva, 2009.

[3] E. Gray and D. Tall, Duality, Ambiguity and Flexibility: A Proceptual View of Simple Arithmetic, The Journal for Research in Mathematics Education, 1994.

[4] S. Kagan, Kooperatív tanulás, Ökonet Kft., Budapest (4:4), 2001.

[5] MatheNetz Gymnasium 6, Westermann Verlag Braunschweig, 2006, 200-227.

[6] Sokszínü Matematika 5, MOZAIK, Szeged, 2005, 233-252.

[7] D. Tall and S. Vinner, Concept image and concept definition in mathematics, with special reference to limits and continuity, Educational Studies in Mathematics 12, 1981, 151-169.

ILEANA MATE

THE LOWER-SECONDARY SCHOOL OF PAPTAMÁSI

PAPTAMÁSI NR. 65

ROMANIA

E-mail: mateilona@yahoo.com

(Received November, 2010) 